\title{
Detector with High Internal Photocurrent Gain Based on $\mathrm{ZnO}: \mathrm{N}$
}

\author{
L.A. Kosyachenko ${ }^{a}$, G.V. LAshKAReV ${ }^{b}$, A.I. IEvtushenko ${ }^{b, *}$, V.I. LAzOrenko ${ }^{b}$, \\ V.M. SKLYARCHUK ${ }^{a}$ AND O.F. SKLYARCHUK ${ }^{a}$ \\ ${ }^{a}$ Chernivtsi National University, 58012 Chernivtsi, Ukraine \\ ${ }^{b}$ Institute for Problems of Material Science, NASU, 03142 Kiev, Ukraine
}

\begin{abstract}
The photoresponsive structures prepared by magnetron sputtering of $\mathrm{ZnO}: \mathrm{N}$ on $p$-Si substrates followed by vacuum evaporation of semi-transparent $\mathrm{Ni}$ film on $\mathrm{ZnO}$ surface were investigated. The mentioned structures show high sensitivity that sharply enhances with increase of applied voltage. Under a bias $5 \mathrm{~V}$, the responsivities at $\lambda=390$ and $850 \mathrm{~nm}$ are equal to $210 \mathrm{~A} / \mathrm{W}$ and $110 \mathrm{~A} / \mathrm{W}$ which correspond to the quantum efficiencies of 655 and 165 , respectively. It is suggested that the observed high response is attributed to internal gain in phototransistor structure containing $\mathrm{Ni} / n-\mathrm{ZnO}$ Schottky contact as emitter junction and $n-\mathrm{ZnO} / p$-Si heterostructure as collector junction.
\end{abstract}

PACS: 81.05.Dz, 81.15.-z, 85.60.Dw

\section{Introduction}

In recent years there has been increased an interest to $\mathrm{ZnO}$-based photodiodes with the $n-\mathrm{ZnO} / p$-Si heterojunction used as a photosensitive element [1-5]. In such photodiodes, the responsivity $0.28 \mathrm{~A} / \mathrm{W}$ was achieved at $670 \mathrm{~nm}$ that corresponds to the quantum efficiency about $0.5[3,5]$ while in Ref. [2] the responsivity at $310 \mathrm{~nm}$ was $0.5 \mathrm{~A} / \mathrm{W}$ that corresponds to the quantum efficiency about 2. In Ref. [6] the fabrication and characterization of an $\mathrm{Au} / n-\mathrm{ZnO} / p$-Si UV enhanced bipolar phototransistor are presented. The sensitivity at $370 \mathrm{~nm}$ of such device is more than $5-10$ times that of a $\mathrm{ZnO} / \mathrm{Si}$ photodiode. In this communication we report on the results of investigation of $\mathrm{Ni} / n-\mathrm{ZnO}: \mathrm{N} / p$-Si structure with quantum efficiency which can achieve several hundreds due to an internal gain.

\section{Photoelectric characteristics of $\mathrm{Ni} / n-\mathrm{ZnO} /$ $p$-Si structure and discussion}

The $\mathrm{ZnO}$ films with thickness $0.1 \mu \mathrm{m}$ were deposited by DC magnetron sputtering in $\mathrm{N}_{2} / \mathrm{Ar}$ plasma on $p$-Si wafers having resistivity $9-10 \Omega \mathrm{cm}$. To compensate oxygen vacancies acting in $\mathrm{ZnO}$ as intrinsic donor defects, we introduce the nitrogen into $\mathrm{ZnO}$ during film deposition by sputtering $\mathrm{ZnO}$ target in $\mathrm{N}_{2} / \mathrm{Ar}(10 / 1)$ gas ambient [7]. A semi-transparent Ni layer with thickness about $10 \mathrm{~nm}$ was deposited as a Schottky contact on the $\mathrm{ZnO}$ surface

* corresponding author; e-mail: earsen@ukr.net by vacuum thermal evaporation. Aluminum ohmic contacts to $p$-Si were also evaporated using the same technique.

The spectral distribution of radiation at the outlet slit of the system was determined in absolute units using a Si reference photodiode D286.

The investigated samples reveal photoresponsivity only at the polarity with low current ("+" to Ni contact, "-" to $p$-Si). As one can see from Fig. 1, the photoresponsivity spectra cover a wide spectral region. Evidently, in the regions $\lambda<500 \mathrm{~nm}$ and $\lambda>500 \mathrm{~nm}$, responsivities are caused by photogeneration of electron-hole pairs in $\mathrm{ZnO}$ and $\mathrm{Si}$, respectively.

Our experiments showed that at a bias voltage higher then $\approx 0.5 \mathrm{~V}$, the responsivity of $\mathrm{Ni} / n-\mathrm{ZnO} / p$-Si structure is higher than the same of Si reference photodiode with $0.45 \mathrm{~A} / \mathrm{W}$ at a maximum. High values of spectral responsivity $S$ mean that photoelectric conversion in $\mathrm{Ni} / n-\mathrm{ZnO} / p$-Si structure is characterized by heightened quantum efficiency $\eta=S h c / \lambda$ (Fig. 2). At the lowest bias voltages, quantum efficiencies $\eta(\lambda)$ at $\lambda=390$ and $850 \mathrm{~nm}$ increase drastically with $V$ but at higher voltages such increase becomes slower. Nevertheless, at $V=5 \mathrm{~V}$ the $\eta(\lambda)$ values at $\lambda=390$ and $850 \mathrm{~nm}$ become equal to 655 and 165 which correspond to the responsivities 211 and $110 \mathrm{~A} / \mathrm{W}$, respectively

All obtained results allow us to assume that the investigated $\mathrm{Ni} / n-\mathrm{ZnO}: \mathrm{N} / p-\mathrm{Si}$ structure is a peculiar kind of bipolar transistor that operates as a photodetector with photocurrent gain, i.e. as a phototransistor [8]. If voltage sign on $\mathrm{Ni}$ contact is positive in respect of $p-\mathrm{Si}, \mathrm{Ni} / n-\mathrm{ZnO}$ emitter junction and $n-\mathrm{ZnO} / p$-Si collector junction are 


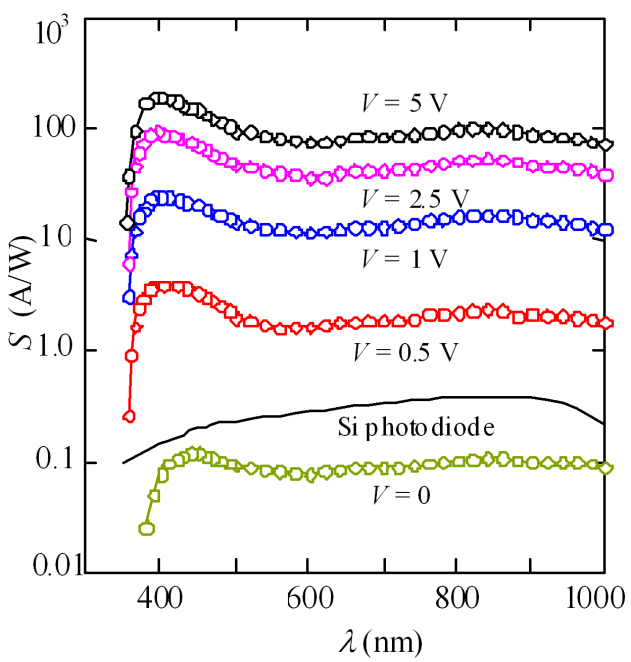

Fig. 1. Spectral response $S$ of $\mathrm{Ni} / n-\mathrm{ZnO}: \mathrm{N} / p$-Si structure at different voltages (circles) and the spectral curve of Si reference photodiode (solid line).

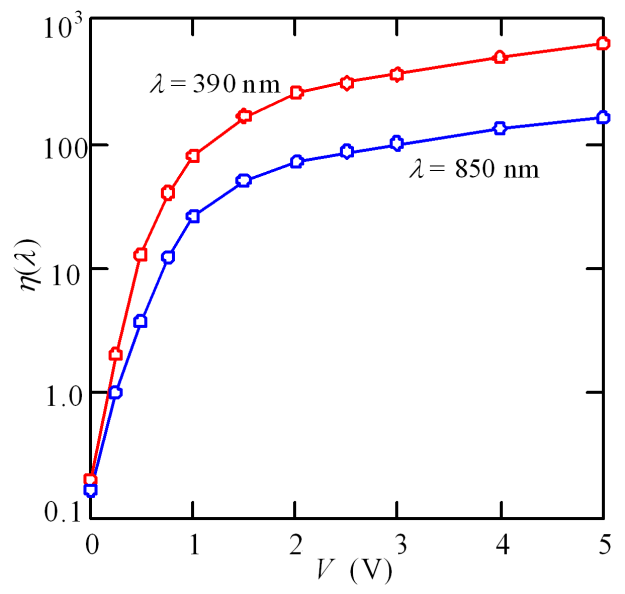

Fig. 2. Voltage dependences of quantum efficiency $\eta(\lambda)$ of $\mathrm{Ni} / n-\mathrm{ZnO}: \mathrm{N} / p-\mathrm{Si}$ structure at 390 and $850 \mathrm{~nm}$.

switched on in the forward and reverse directions, respectively, just as in the bipolar transistor with a common emitter. Electron-hole pairs generated by the absorbed photons in the space-charge region of $n-\mathrm{ZnO} / p$-Si heterojunction are separated by the electric field in opposite directions constituting the "primary" photocurrent and participating in forming the observed spectra. In both cases electrons are injected into the neutral part of the $\mathrm{ZnO}$ film, i.e. in transistor base. To provide stationary process, the same quantity of holes is injected in $\mathrm{ZnO}$ from the emitter (i.e., from the Ni contact). Of course, band bending at the $\mathrm{Ni} / n-\mathrm{ZnO}$ Schottky contact should be large to provide the formation of inversion $p-n$ junction and thus effective injection of holes into the base.
In a bipolar transistor, the current of minority carriers injected in the base from the emitter is amplified by a factor of $\beta=\alpha /(1-\alpha)$, where $\beta$ is the common-emitter current gain of the transistor, and $\alpha$ is the common-base current gain. The current gain $\alpha$ depends on a ratio between the base thickness $d$ and the diffusion length of minority carriers $L_{\mathrm{p}}=\left(\tau_{\mathrm{p}} D_{\mathrm{p}}\right)^{1 / 2}$, where $\tau_{\mathrm{p}}$ and $D_{\mathrm{p}}$ are the lifetime and diffusion coefficients of holes, respectively. Accepting for an estimation the hole mobility $\mu_{\mathrm{p}}$ in $\mathrm{ZnO}$ equal to $1-10 \mathrm{~cm}^{2} /(\mathrm{V} \mathrm{s})[9 \mathrm{1}$ ], from Einstein's ratio one can obtain $D_{\mathrm{p}}=\mu_{\mathrm{p}} k T / q=0.025-0.25 \mathrm{~cm}^{2} / \mathrm{s}$ at $300 \mathrm{~K}$. Accepting further $\tau_{\mathrm{p}}=10^{-8}-10^{-7} \mathrm{~s}$ for holes in $\mathrm{ZnO}[10]$, for the hole diffusion length one can obtain $L_{\mathrm{p}}=0.5-1.5 \mu \mathrm{m}$ that is longer than the film thickness $d=0.1 \mu \mathrm{m}$. If $L_{\mathrm{p}}>d$, the value of the common-base current gain $\alpha$ is close to 1 . It means that $\beta \gg 1$, i.e., a photocurrent in $\mathrm{Ni} / n-\mathrm{ZnO} / p$-Si structure is significantly amplified.

\section{Conclusions}

Our experimental results correlate with the assumption that the investigated $\mathrm{Ni} / n-\mathrm{ZnO}: \mathrm{N} / p$-Si structure possesses properties of the phototransistor providing internal gain of the photocurrent. The parameters of the structure (the $\mathrm{ZnO}$ thickness layer and the lifetime of minority carriers) allowed us to get a gain exceeding several hundreds at moderate bias $\leq 5 \mathrm{~V}$.

\section{References}

[1] J.Y. Lee, Y.S. Choi, W.H. Choi, H.W. Yeom, Y.K. Yoon, J.H. Kim, S. Im, Thin Solid Films 420-21, 112 (2002).

[2] I.-S. Jeong, Jae Hoon Kim, S. Im, Appl. Phys. Lett. 83, 2946 (2003).

[3] C.H. Park, J.Y. Lee, S. Im, T.G. Kim, Nuclear Instrum. Methods Phys. Res. B 206, 432 (2003).

[4] C.H. Park, I.S. Jeong, H.S. Bae, T.G. Kim, S. Im, Nuclear Instrum. Methods Phys. Res. B 216, 127 (2004).

[5] H.X. Qi, Q.S. Li, B. Zhao, M.M. Zheng, X.S. Li, N. Zhang, Mater. Sci. Techn. 24, 1002 (2008).

[6] G. Junfu, X. Jiachun, D. Li, H. Guanghong, L. Bixia, F. Zhuxi, Chinese J. Semicond. 27, 5 (2006).

[7] A. Ievtushenko, G. Lashkarev, V. Lazorenko, V. Karpyna, V. Sichkovskyi, L. Kosyachenko, V. Sklyarchuk, V. Bosy, F. Korzhinski, A. Ulyashin, V. Khranovskyy, R. Yakimova, Acta Phys. Pol. A 114, 1123 (2008).

[8] S.O. Kasap, Optoelectronics and Photonics Prentice-Hall, New Jersey 2001, p. 237.

[9] Ü. Özgür, Ya.I. Alivov, C. Liu, A. Teke, M.A. Reshchikov, S. Doğan, V. Avrutin, S.-J. Cho, H. Morkoç, J. Appl. Phys. 98, 041301 (2005).

[10] S.J. Pearson, D.P. Norton, Y.W. Ifeo, T. Steiner, Prog. Mater. Sci. 50, 293 (2005). 